\title{
Psychiatric co-morbidity in primary care and hospital referrals, Saudi Arabia
}

N.A. Qureshi,' T.A. Al-Habeeh, ${ }^{2}$ Y.S. Al-Ghamdy, M.E.M.A. Magzoub4 and H.T. van derMolen

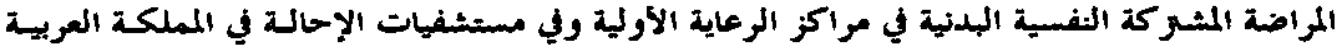
المستصوية

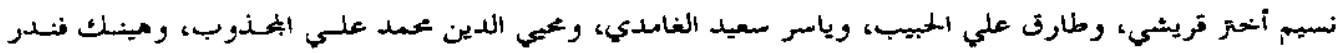
مولين

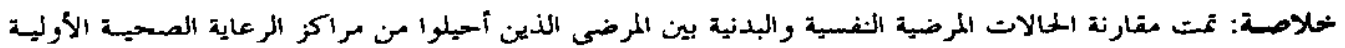

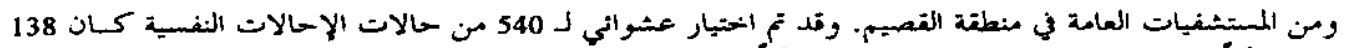

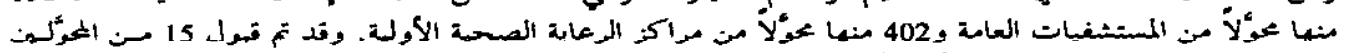

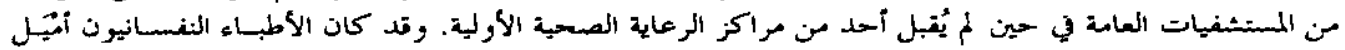

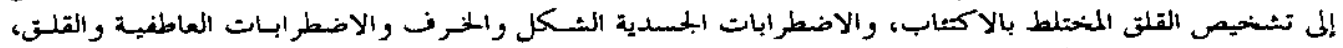

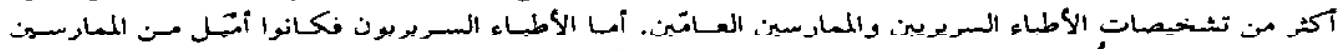

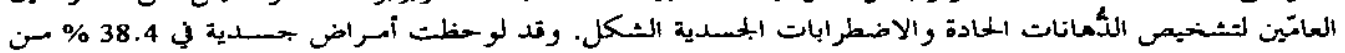

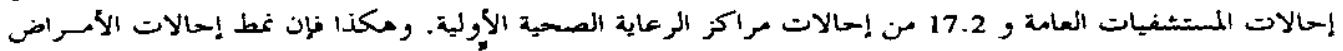

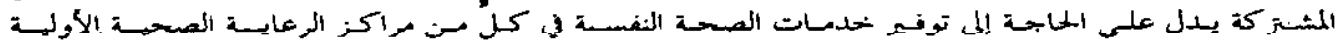

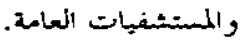

ABSTRACT Psychiatric and physical morbidities among patients referred from primary health care (PHC) centres and general nospltals (GH) in A-Qassim reglon were compared. Thus, 540 psyctialric relerrals (GH $=138 ; \mathrm{PHC}=402$ ) were selected randomly. Fifteen GH patients but no PHC patients were referred for admission. Psychiatrists made more diagnoses of dementia, affective and anxiety disorders, mixed anxietydoproceion and somatoform disordors than clinicians and general practitioners (GPs). Clinicians made sionificantly more diagnoses of acute psychoses and somatotorm disorders than GPs. Physical morbidity was noted in $38.4 \%$ and $17.2 \%$ of GH and PHC referrals respectively.

Comorbidité psychiatrique chez des cas adressés en orientation-recours par des centres de soins de santé primalres et des hópitaux en Arabie saoudite

RESUME Les affections physiques et psychiatriques dans les cas adressés en orientation-recours par les contros de soins de șanté primaires (SSP) et les hôpitaux généraux (HG) dans la Réginn d'Al-Qassim ont été comparées. Cinq cent quarante (540) cas psychiatriques adressés en orientation-recours ( $H G=138$; SSP $=402$ ) ont été sélectionnés au hasard. Quinze patients HG - mais aucun patient SSP - ont été adressés en orientation-recours pour admission. Les psychiatres ont établi davantage de diagnostics de démence, de troubles affectifs et anxieux, de trouble mixte anxiété-dépression et de troubles somatoformes que les cliniciens et les généralistes. Les cliniciens ont posé davantage de diagnostics de psychoses aiguës et de troubles somatoformes que les généralistes. Une affection physique a été notée chez plus de $38,4 \%$ et $17,2 \%$ des cas d'orientation-recours des hópitaux generaux et des SSP, respectivement.

'Buraidah Mental Health Hospital, Buraidah, Saudi Arabia.

2Division of Psychiatry, King Khalid University Hospital, Riyadh, Saudi Arabia.

'Director-General of Health Affairs, Al-Qassim Region, Saudi Arabia.

'Department of Community Health, College of Applied Medical Sciences, Riyadh, Saudi Arabia.

${ }^{5}$ Department of Psychology. Erasmus University. Rotterdam. The Netherlands. 


\section{Introduction}

The co-occurrence of psychiatric and physical disorders reported among primary care and hospital patients has implications that are etiological, diagnostic, therapeutic, prognostic, economic, planning and research [1-7]. In the context of psychiatric co-morbidity among primary care and hospital patients, a variety of psychiatric disorders are reported to co-exist with cardiovascular, gastrointestinal, neurological, respiratory and endocrine disorders. The identification of psychiatric disorders and medical illnesses among medical and psychiatric patients is essential for the delivery of integrated treatments in a cost-effective manner. Patients with psychiatric disorders and patients with physical diseas es are at higher risk of developing physical diseases [8] and psychiatric disorders [9] respectively, if left untreated. Nlthough this relation is complex, each disorder complicates the other. Chronic co-persistence, for instance, is associated with increased length of stay in the hospital and with psychological, social and physical disability $[10,11]$.

Unlike Western countries where primary health care (PHC) psychiatry and general hospital (GH) psychiatry are fairly well developed, many Arab countries face challenges in developing and delivering mental health services, in particular, at the community level. Although the projected prevalence of psychiatric disorders in PHC centres and GHs in these countries is high $(>60 \%)$, there is as yet no adequate provision for delivering mental health services to patients with peychiatric manifestations. Therefore, most patients with identified psychiatric morbidities (47\%) are referred to secondary-level eare [12]. Nonctheless, approximately $45 \%$ of patients are reported to have hidden psychiatric morbidities and are not referred [13].
Psychiatric referrals are important to the study of psychiatric and physical morbidity in PHC centres and GHs. The patients are usually referred by the general practitioners (GPs) and clinicians who evaluate them. Although some of these patients remain psychologically undiagnosed or the diagnoses are not noted in their referral letters, psychiatrists evaluate each patient and makc a diagnosis with treatment recommendations. The current study comparatively analysed psychiatric referrals in order to project the pattern of psychiatric co-morbidity identified by psychiatrists, clinicians and GPs.

\section{Methods}

The referral system, the random selection of the 540 referral letters and the method of collection of psychiatric diagnoses and treatments recommended by the psychiatrists are described elsewhere [14].

The referral system was introduced to Saudi Arabia in 1989. After its introduction, it was decided that the referral system guidelines were to be strictly followed throughout Saudi Arabia. Nevertheless, many patients still come to psychiatric hospitals for consultation without referral letters. This trend is attributed to four causes.

- Psychiatric facilities and personnel, including psychologically trained doctors and nurses, are not available at PHC centres.

- Psychotropic drugs for filling prescriptions are not available at PHC centres.

- There are no staff trained in psychotherapy or counselling at PHC centres.

- Although contrary to referral system guidelines, hospital administration allows patients without referrals to be evaluated and managed by psychiatric staff.

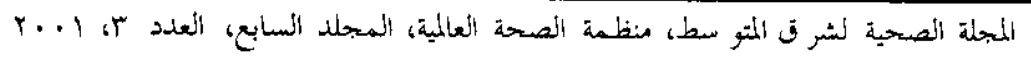


In our study, 540 referral letters that were randomly collected from January 1999 to January 2000. First, we selected randomly 10 sections of the 30 racks of the psychiatric record centre in which outpatient files were kept. Each section contained approximately $110-125$ files. Then, we removed all files (1110) and the files containing referral forms were retained. The appended referral letters in these files were either photocopied or the written information was transferred to standard ministry of health referral forms. Some files had the original referral form plus a duplicate photocopy, which we detached. During the data collection period, the first author also met with patients in outpatient clinics and those files with referral letters were also photocopied. Patient's name was used to ensure that no referral letter was included twice. Both the first diagnosis of and the preseribed treatments for the patient by the psychiatrist were taken from each file and simultaneously noted on the photocopied referral forms.

A standard ministry of health referral letter contains items such as: date, nationality of the patient, name of PHC centre, age, referred speciality and hospital, complaints, duration of complaints, treatments, reason for and type of referral, doctor's name, and diagnosis. The hospital referral forms also contain more or less similar items.

We calculated the frequency distribution of nationality, types of referrals, reasons for referrals and duration of illness. Types of referral were divided into elcetive (i.e. ordinary) or urgent (i.e. requiring immediate medical/psychiatric help including special treatment for saving life). Bccause almost all patients were referred, type of referral was not recorded in many letters. Therefore, we considered referrals that did not have "urgent" written or marked on the referral letters as "ordinary". Reasons for referral were categorized into six types: overall management and care; diagnostic and treatment; evaluation, diagnosis and treatment; investigation, treatment and follow-up; admission; and personal request. Most referrals had overlapping reasons. We categorized duration of illness as either less than 6 months or more than 6 months. We also reviewed each patient's file in order to record diagnoses and drug treatments prescribed by the psychiatrists.

Upon presentation, patients in our study usually followed procedure to diagnosis. Outpatient files were opened for all new patients consulting the Buraidah Mental Health Hospital, whether with or without a referral letter. The psychiatric specialist determined procedure following a circumscribed interviow, which guided the psychiatric caseness. After this, the patient was seen by the social worker in order to collect social data. Then the resident doctor conducted both physical and systemic examinations of the patient. Thereafter, the resident doetor consulted with the psychiatrist about the patient in order to plan management including diagnosis, treatment and follow-up. Any diagnostically difficult patients were discussed in the psychiatric consensus meeting at the hospital. As the hospital officially uses the International classification of mental diseases (ICD-10), if the psychiatric specialist had knowledge of DSM-111R and DSM-1V classifications they were used. Under certain circumstances, the clinical psychologist also evaluated some now patients. Gcncrally, we feel that the diagnoses made by the psychiatrists were robustly reliable.

During previous programmes conducted in Al-Qassim region $[15,16]$, some of the GPs and clinicians were trained in clinical psychiatry including a brief discussion on ICD-10. Therefore, diagnostic labelling 
of referred patients partially coincided with ICD-10 classifications of mental diseases.

The data were analysed with frequency distributions. In addition, the chi-squared analysis was used for categorical parameters. A $P$-value equal or less than 0.05 was considered significant. We used SPSS 7.5 for data analysis.

\section{Results}

More non-Saudis were referred for psychiatric management from $\mathrm{GHs}$ than from PHC centres $\left(\chi_{1}^{2}=14.339, P<0.001\right)(\mathrm{Ta}-$ ble 1). A statistically significant proportion of patients with urgent psychiatric problems came from $\mathrm{GH}$ referrals whereas more PHC patients were referred on an elective basis $\left(\chi^{2}=58.524, P<0.001\right)$. Overall management and care and evaluation, diagnosis and treatment were significant reasons noted in referrals from primary care. On the other hand, diagnosis, treatment, psychological investigation and overall follow-up were significant reasons in $\mathrm{GH}$ referrals $\left(\chi_{3}^{2}=53.612, P<0.001\right)$. Admission as a reason was noted in $15 \mathrm{GH}$ referrals $(10.9 \%)$. One patient from primary health care $(0.2 \%)$ was referred on per-

Table 1 Socioclinical features of referred patients

\begin{tabular}{|c|c|c|c|c|c|c|c|}
\hline \multirow{2}{*}{ Socioclinical feature } & \multicolumn{2}{|c|}{$\mathrm{GH}(n=138)$} & \multicolumn{2}{|c|}{ PHC centre $(n=402)$} & \multirow[t]{2}{*}{$x^{2}$} & \multirow[t]{2}{*}{ df } & \multirow[t]{2}{*}{ Pvalue } \\
\hline & No. & $\%$ & No. & $\%$ & & & \\
\hline \multicolumn{8}{|l|}{ Nationality } \\
\hline Saudi & 113 & 81.9 & 380 & 94.5 & & & \\
\hline Non-Saudi & 12 & 8.7 & 8 & 2.0 & 14.339 & 2 & $<0.001$ \\
\hline Unrecorded & 13 & 9.4 & 14 & 3.5 & & & \\
\hline \multicolumn{8}{|l|}{ Type of referral } \\
\hline Elective & 106 & 76.8 & 392 & 97.5 & & & \\
\hline Urgent & 32 & 23.2 & 10 & 2.5 & 58.524 & 1 & $<0.001$ \\
\hline \multicolumn{8}{|l|}{ Reason for referral } \\
\hline Overall management & 24 & 17.4 & 126 & 31.3 & & & \\
\hline Diagnosis and treatment & 21 & 15.2 & 15 & 3.7 & & & \\
\hline Evaltuation, diagnosis and & & & & & & & \\
\hline $\begin{array}{l}\text { treatment } \\
\text { Investigation, treatment }\end{array}$ & 48 & 34.8 & 228 & 56.7 & & & \\
\hline and follow-up & 26 & 18.8 & 28 & 7.0 & 53.612 & 3 & $<0.001$ \\
\hline Admission & 15 & 10.9 & 0 & - & & & \\
\hline Personal request & 0 & - & 1 & 0.2 & & & \\
\hline Unrecorded & 4 & 2.9 & 4 & 1.0 & & & \\
\hline \multicolumn{8}{|l|}{ Duration of illness (months) } \\
\hline 46 & 40 & 29.0 & 114 & 28.3 & & & \\
\hline$>6$ & 48 & 34.8 & 101 & 25.1 & 1.431 & 2 & 0.232 \\
\hline Unrecorded & 50 & 36.2 & 187 & 46.6 & & & \\
\hline
\end{tabular}

$G H=$ general hospital.

PHC = primary health care.

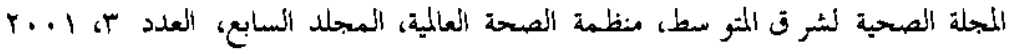


Table 2 Peychiatric diagnoces by GH and PHC roforrale

\begin{tabular}{|c|c|c|c|c|c|c|c|c|}
\hline \multirow[t]{3}{*}{ Diagnosis } & \multicolumn{4}{|c|}{ GH referrals $(n=138)$} & \multicolumn{4}{|c|}{ PHC referrals $(n=402)$} \\
\hline & \multicolumn{2}{|c|}{$\begin{array}{c}\text { Psychiatrist } \\
\text { diagnosis }\end{array}$} & \multicolumn{2}{|c|}{$\begin{array}{l}\text { Doctor } \\
\text { diagnosis }\end{array}$} & \multicolumn{2}{|c|}{$\begin{array}{c}\text { Psychiatrist } \\
\text { diagnosis }^{\circ}\end{array}$} & \multicolumn{2}{|c|}{$\frac{\text { GP }}{\text { diagnosis }^{b, c}}$} \\
\hline & No. & $\%$ & No. & $\%$ & No. & $\%$ & No. & $\%$ \\
\hline Dementia & 13 & 9.4 & 2 & 1.4 & 20 & 5.0 & 4 & 1.0 \\
\hline Schizophrenic disorder & 25 & 18.1 & 21 & 15.2 & 62 & 15.4 & 19 & 4.7 \\
\hline Acute psychosis & 7 & 5.1 & 7 & 5.1 & 8 & 2 & 6 & 1.5 \\
\hline Mood disorders & 34 & 24.6 & 23 & 16.7 & 118 & 29.4 & 66 & 16.4 \\
\hline Anxiety disorders & 19 & 13.8 & 18 & 13.0 & 70 & 17.4 & 47 & 11.7 \\
\hline Anxiety-depression & 7 & 5.1 & 6 & 4.3 & 26 & 6.5 & 9 & 2.2 \\
\hline Somatoform disorders & 14 & 10.2 & 11 & 8.0 & 22 & 5.2 & 7 & 1.7 \\
\hline Seizure disorders & 6 & 4.3 & 5 & 3.6 & 18 & 4.5 & 15 & 3.7 \\
\hline Childhood disorders & 1 & 0.7 & 0 & - & 30 & 7.5 & 17 & 4.2 \\
\hline Psychosomatic disorders & 0 & - & 4 & 2.9 & 13 & 3.2 & 3 & 0.7 \\
\hline Miscellaneous & 8 & 5.9 & 19 & 13.8 & 14 & 3.5 & 29 & 7.2 \\
\hline Diagnoses missing & 4 & 2.9 & 22 & 15.9 & 1 & 0.2 & 180 & 44.8 \\
\hline
\end{tabular}

" Poychiatriste made more diagnoses of dementia and affective disorders than GH dootors but the difference was not statistically significant $\left(x_{0}^{2}=12.798, \mathrm{P}>0.05\right)$.

$\mathrm{GH}$ clinicians made more diagnoses of acute psychosis, schizophrenic disorders, anxiety-depression and somatoform disorders than GPs $\left(\chi_{B}^{2}=18.885, P<0.01\right)$.

Psychiatrists made more diagnoses of dementia, sohizophronis disorders, mood diaorders, anxiety

disorders, anxiety-depression and somatoform disorders than GPs $\left(x_{g}^{2}=33.674, \mathrm{P}<0.001\right)$.

$\mathrm{GH}=$ general hospital.

$P H C=$ primary health care.

$C P=$ gonoral praotitioner.

sonal request. Duration of illness when arbitrarily divided into two categories, i.e. less than or more than 6 months, did not differentiate between the two sources of referrals $\left(\chi_{1}^{2}=1.431, P=0.232\right)$. However, when we divided duration into three categorics, i.e 3 months or less, 4-6 months or more than 6 months, a statistically significant proportion of patients whose illness was of less than 3 months duration were referred from $\mathrm{GHs}\left(\chi_{2}^{2}=15.926, P<\right.$ 0.001 ).

Psychiatrists and $\mathrm{GH}$ clinicians did not note diagnoses in 4 of $138(2.9 \%)$ and 22 of $138(15.9 \%)$ referrals respectively (Ta- ble 2). Among PHC referrals, psychiatrists and GPs did not note diagnoses in 1 of 402 $(0.2 \%)$ and 180 of $402(44.8 \%)$ referrals respectively. The pattern of psychiatric diagnosis by referral indicated that $\mathrm{GH}$ clinicians made more diagnoses of acute psychotic disordcrs, schizophrenic disorders, mixed anxiety-depression and somatoform disorders than GPs $\left(\chi_{8}^{2}=18.885\right.$, $P<0.01)$. Although statistically insignificant, psychiatrists made more diagnoses of dementia and affective disorders than clinicians $\left(\chi_{8}^{2}=12.798, P>0.05\right)$. Psychiatrists made significantly more diagnoses of dementia, schizophrenic disorders, mood 
disorders, anxiety disorders. mixed anxiety-depression and somatoform disorders than GPs $\left(\chi_{8}^{2}=33.674, P<0.001\right)$.

Among GH referrals, psychiatrists diagnosed only 1 case with a childhood disorder $(0.7 \%)$, whereas GH clinicians did not note any childhood problems. As regards psychosomatic disorders, psychiatrists made no diagnosis of such problems but GH clinicians noted these disorders in 4 referral letters $(2.9 \%)$. Among $\mathrm{PHC}$ referrals, psychiatrists diagnosed childhood and psychosomatic disorders in $30(7.5 \%)$ and 13 (3.2\%) referred patients respectively, whereas GPs noted these respectively in 17 $(4.2 \%)$ and $3(0.7 \%)$ referred patients.

The diagnoses of physical disorders (122 of 540 patients, $22.6 \%$ ) were noted in $53 \mathrm{GH}$ referrals $(38.4 \%)$ and in only 69 PHC referrals (17.2\%) (Table 3). Hypertension was more common among $\mathrm{PHC}$ referrals, whereas diabetes mellitus, gastrointestinal disorders and respiratory disorders were more common among $\mathrm{GH}$ referrals.

\section{Discussion}

This study comparatively analysed socioclinical parameters and patterns of psychiatric and physical morbidity noted in psychiatric referrals from $\mathrm{PHC}$ centres and GHs. Although most of the referred patients from both GHs and PHC centres were Saudis, among non-Saudis surprisingly more were referred from GHs than from PHC centres. Most of these non-Saudi patients were suffering from acute behavioural changes upon receiving bad news from home or from tremendous collective stresses associated with psychiatric morbidity $[17,18]$. A carefully designed study to assess the psychological and physical health of the expatriate community in Saudi Arabia might be useful. With the rapid establishment of private medical services,
Table 3 Physioal dlagnoses for GH and PHC referrals

\begin{tabular}{|c|c|c|c|c|}
\hline \multirow[t]{2}{*}{ Diagnoses } & \multicolumn{2}{|c|}{$\mathrm{GH}(n=138)$} & \multicolumn{2}{|c|}{ PHC $(n=402)$} \\
\hline & No. & $\%$ & No. & $\%$ \\
\hline Diabetes mellitus & 10 & 7.3 & 15 & 3.7 \\
\hline Hypertension & 2 & 1.4 & 15 & 3.7 \\
\hline $\begin{array}{l}\text { Gastrointestinal } \\
\text { disorder }\end{array}$ & 12 & 8.7 & 4 & 1.0 \\
\hline $\begin{array}{c}\text { Neurological } \\
\text { disease }\end{array}$ & 10 & 7.3 & 23 & 5.7 \\
\hline $\begin{array}{l}\text { Rospiratory } \\
\text { disease }\end{array}$ & 7 & 5.1 & 3 & 0.7 \\
\hline Miscellaneous & 12 & 8.7 & 9 & 2.2 \\
\hline Total & 53 & 38.4 & 69 & 17.2 \\
\hline
\end{tabular}

$G H=$ general hospital.

$P H C=$ primany health care .

non-Saudis have restricted access to medical services in public GHs and PHC centres. However, they do have relatively good access to emergency medical services in those settings. Similarly, non-Saudis have full access to psychiatric services available in psychiatric hospitals and to psychiatric clinics based in GHs as private psychiatric services are not yet fully developed in Saudi Arabia.

We found that the more serious referrals were more commonly $\mathrm{GH}$ referrals than PHC referrals. Furthermore, most acule referrals $(27$ of $88,36.7 \%$ versus 50 of $215,23.3 \%)(P<0.001)$ were from GHs, which also referred $10.9 \%$ of patients for adnission purposes. This might suggest that GHs rather than PHC centres deal with more acute or serious psychiatric conditions, i.e. acute organic/runctional psychotic conditions, acute depressive and anxiety disorders, grief reactions and adjustment disorders. The severity of psychiatric disorders has been reported to be high among inpatient admissions in other reports

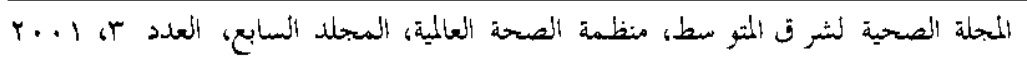


[19]. In contrast, primary care referrals categorized as urgent did not in fact differ in severity of illness from those with ordinary referral [20]. Because of this, we emphasize that all GHs should develop psychiatric consultation liaison services. PHC also needs a step-wise approach for the establishment of mental health centres in order to provide proper mental health services to patients.

More than one reason or overlapping reasons for referring patients were given for most referrals from both PHC centres and GHs. Reasons included evaluation, investigation, diagnosis, treatment and follow-up because no mental health delivery systems are available at PHC centres or in most GHs. This differs from our previous research in which we found distinct but not overlapping reasons among non-psychiatric referral [2I].

Personal requests for psychiatric referral in this study $(0.2 \%)$ were very low compared with our previous study (4.9\%) [21]. This could be attributed to the social stigma attached to psychiatric disorders, speciality and hospitals [15]. The clinical relevance of this might be that in the absence of psychologically trained staff in the hospitals and primary care, psychiatric patients are referred for multiple reasons. This necessitates the assessing mental health professionals performing comprehensive evaluation including diagnostic formulation, treatment plan and follow-up care for each referred patient.

As in other research [22], we found that acute organic brain conditions, acute psychoses, schizophrenic disorders and somatoform disorders were more common among $\mathrm{GH}$ referrals than among PHC referrals. Furthermore, consistent with another shidy of psychiatric morbidity among GH inpatients [23], affective and anxiety disorders and somatoform disorders fol- lowed by dementia were the most common disorders found among GH referred patients. According to some researchers, these diagnoses determine referrals to psychiatric hospitals [24]. In contrast, affective disorders, anxiety disorders, schizophrenic disorders and mixed anxiety-depression followed by somatoform disorders were the common psychopathologies found among PHC referrals. Hence, psychiatric diagnoses by referrals from primary care and hospitals were primarily in agreement. More or less similar patterns of psychiatric disorders in primary care have been reported in other studies [25]. Furthermore, despite somatization being the most common psychiatric phenomenon in primary care, GP recognition rate of somatoform disorders has previously heen found to be low [26], which is in agreement with our findings. The identification and proper management of psychiatric disorders among GH and PHC patients is important as it prevents the development of physical and psychological disabilities associated with role impairment and reduces the length of hospital stay in a cost-effective way.

Finally, a variety of childhood disorders, including mental subnormality, enuresis and encopresis, speech disorders, nail-biting, school phobia and attention deficit hyperactivity disorders, were exclusively noted among PHC referrals. This finding raises some questions. Are these childhood disorders mostly referred to paediatricians within the GHs themselves? Are these childhood disorders only managed by paediatricians without being referred to psychiatric hospitals? Are GPs forced by way of non-availability of drugs or lack of management skills to refer such patients to psychiatrists? Does the prevalence of these disorders differ between these two sources of referral? By and large, there is no epide- 
miological data on childhood psychiatric disorders in Saudi Arabia. Similarly, there are no specific provisions for child psychiatric services in psychiatric hospitals or in general hospitals. Therefore, we suggest that child psychiatric clinics should be opened in psychiatric and general hospitals. Child psychiatry warrants proper planning, development and research in Arab countries such as ours.

Concurrent physical morbidity was more common among $\mathrm{GH}$ referrals than among PHC referrals, a finding consistent with another study [22]. Hypertension was more common among PHC referrals, whereas diabetes mellitus, gastrointestinal and respiratory disorders were more common among GH referrals. Unlike our two previous studics of psychiatric inpatients [27] and elderly outpatients [28], this study found a lower rate of physical morbidity (122 of 540 patients, $22.6 \%$ ). This inconsistency might be attributed both to psychiatric inpatients who tend to have higher rate of physical discases and age. It has boen reported that the prevalence of physical morbidity increases with increasing age [29]. However, the most frequently observed physical diseases in those studies $[27,28]$ were similar to the present study. Notably, diabctes, hypertension and other cardiovascular illnesses were co-morbid with depression [30], which was the most common disorder in the present study.

Although we did not screen outpatient files of these referred patients for noted physical disorders, it has been documented that psychiatrists do not recognize and/or underdiagnose [29] physical disorders among psychiatric populations [31]. The clinical implication of revealing physical morbidity in psychiatric patients is that psychiatrists should always assess the physical condition of referred patients. Accordingly, a consultation from medical staff should always be sought. We further suggest that establishing a psychiatrymedical unit in a psychiatric hospital will circumvent many of the problems faced while coordinating medical-liaison services. It should be noted that the presence of physical illnesses, such as circulatory and respiratory conditions, among elderly psychiatric inpatients with dementia is associated with increased mortality [6]. Overall, psychiatric patients with physical co-morbidity certainly require higher medical care in a proper setting. This could be offered by a multidisciplinary team of professionals which includes medical and psychiatric consultants.

In light of the findings of our study and other reviewed atudies, we suggest that GH and PHC psychiatry should be further developed in Saudi Arabia.

\section{Acknowledgements}

We thank Dr M. Khalil, Department of Professional Development and Regional Medical Education and Research Centre, King Fahd Specialist Hospital, for his statistical expertise. We also thank Professor H.G. Schmidt, Erasmus University, Netherlands for his expert advice and guidance.

\section{References}

1. Fulop G, Strain JJ. Diagnosis and treatment of psychiatric disorders in medically ill inpatients. Hospital and community psychiatry, 1991, 42:389-94.
2. Booth BM, Blow FC, Cook CA. Functional impairment and co-occurring psychiatric disorders in medically hospitalized

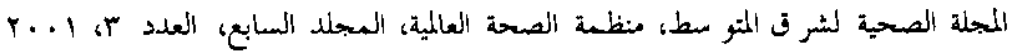


men. Archives of internal medicine, 1998, 158:1551-9.

3. Kisely SR, Goldberg DP. Physical and psychiatric co-morbidity in general practice. British journal of psychiatry, 1996, 169:236-42.

4. Dewa CS, Lin E. Chronic physical illness, psychiatric disorder and disability in the workplace. Social science and medicine, 2000, 51:41-50.

5. Sloan DM et al. A five-year study on the interactive effects of depression and physical illness on psychiatric unit length of stay. Psychosomatic medicine, $1999,61: 21-5$.

6. Kamara SG, Peterson PD, Dennis JL. Prevalence of physical illness among psychiatric inpatients who die of natural causes. Psychiatric services, 1998, 49:788-93.

7. Peveler R, Kilkenny L, Kinmonth AL. Medically unexplained physical symptoms in primary care: a comparison of self-report screening questionnaires and clinical opinion. Journal of psychosomatic research, 1997, 42:245-52.

8. Segal SP, Vandervoort DJ, Liese LH. Residential status and the physical health of a mentally ill population. Health and social work, 1993, 18:208-14.

9. Hotopf $M$ et al. Temporal relationships between physical symptoms and psychiatric disorder. Results from a national birth cohort. British journal of psychiatry, 1998, 173:255-61.

10. Saravay SM, Lavin M. Psychiatric co-morbidity and length of stay in the general hospital. A critical review of outcome studies. Psychosomatics, 1994, 35:233-52.

11. Ormel $\mathrm{J}$ et al. Common mental disorders and disability across cultures. Results from the WHO Collaborative Study on Psychological Problems in General
Health Care. Journal of the American Medical Association, 1994, 272:1741-8.

12. Al-Jaddou $\mathrm{H}$, Malkawi A. Prevalence, recognition and management of mental disorders in primary health care in northern Jordan. Acta psychiatrica scandinavica, 1997, 96:31-5.

13. Al-Haddad MK et al. Psychiatric morbidity in primary care. Eastern Mediterranean health journal, 1999, 5:21-6.

14. Qureshi NA et al. An analysis of psychiatric referrals, Saudi Arabia. Arab journal of psychlatry, 2001, 12.

15. Qureshi NA et al. The attitudes of primary care physicians to psychiatry. Saudi medical journal, 1995, 16:217-21.

16. Qureshi NA et al. Integration of mental health into primary health care. Preliminary observations of continuing implementation phase. Saudi medical journal, 2001, 22:899-906.

17. Cropley $M$, Steptoe A, Joekes K. Job strain and psychiatric morbidity. Psychology and medicine, 1999, 29:14116.

18. Odell SM et al. Determinants of general practitioner rocognition of psychological problems in a multi-ethnic inner-city health district. British journal of psychiatry, 1997, 171:537-41.

19. Weinberg $A$ et al. Severity of psychiatric disorder in day hospital and inpatient admissions. Acta psychiatrica scandinavica, 1998, 98:250-3.

20. Herran A et al. Derivación de los pacientes con enfermedad mental desde Atención Primaria a Salud Mental. [Referrals of patients with mental disordere from primary care to mental health units.] Actas espanolas de psiquiatria, 2000, 28:13-21.

21. Al-Amrl AH et al. A descriptive study of referral letters in three rural primary health care centres in Al-Qassim region, King- 
dom of Saudi Arabia. International journal of health education, 1997, 35:87-90.

22. Creed $F$ et al. Psychiatric referrals within the general hospitals: comparison with referrals to general practitioners. British journal of psychiatry, 1993, 162:204-11.

23. de Almeida $J M$ et al. Morbilidade psiquiatrica nos doentes internados no hospital geral. [Psychiatric morbidity in general hospital inpatients.] Acta medica portuguesa, 1992, 5:575-9.

24. Viinamaki $\mathrm{H}$ et al. Factors predictive of referral to psychlatrlc hospltal among general hospital psychiatric consultations. Acta psychiatrica scandinavica, 1998, 97:47-54.

25. Berardi D et al. Mental, physical and functional status in primary care attenders. International journat or psychiatric medicine, 1999, 29:133-48.

26. Weich $S$ et al. Somatic presentation of psychiatric morbidity in general practice. British journal of general practice, 1995, 45:143-7.

27. Qureshi NA, Al-Quraishi NY, Hegazy IS. Some characteristics of mental patients admitted to psychiatric hospital. Arab journal of psychiatry, 1991, 2:146-58.

28. Qureshi NA, Hegazy IS. Pattern of psychiatric disorders among elderly patients ( $>50 \mathrm{yrs}$ ) attending psychiatric outpatient clinics at the Buraidah Mental Health Hospital, Buraidah, Al-Qassim, Saudi Arabia. Arab journal of psychiatry, 1994, 5:48-56.

29. Rabinowitz J et al. Physical illness among all discharged psychiatric inpatients in a national case register. Journal of mental health administration, 1997 , 24:82-9.

30. Adamis D, Ball C. Physical morbidity in elderly psychiatric inpatients: prevalence and possible relations between the major mental disorders and physical illness. International journal of geriatric psychiatry, 2000, 15:248-53.

31. Knutsen $E$, DuRand $C$. Previously unrecognizod physical illnoseos in peychiatric patients. Hospital and community psychiatry, 1991, 42:182-6. 